\title{
DSR Route Information based IEEE 802.11g under the Influence of Node-Mobility
}

\author{
Vishal Sharma \\ Shaheed Bhagat Singh State \\ Technical Campus \\ (A Government Establishment) \\ Ferozepur
}

\author{
Vijay Banga \\ Amritsar College of Engineering \\ \& Technology, \\ (ACET), Amritsar
}

\author{
Mandeep Kaur \\ Amritsar College of Engineering \& \\ Technology, \\ (ACET), Amritsar
}

\begin{abstract}
To provide efficient internet access to mobile users without any disruption of services in conjunction with optimum QoS, the problem of mobility-induced route failures needs to overcome considerably in MANETs. This work is an effort made for the exhaustive investigation, to ascertain the impact of mobility speed of mobile nodes over the performance of DSR route information based IEEE 802.11g MANET at high data rate of $54 \mathrm{Mbps}$, not reported in previous work. This work is demonstrated by using OFDM radio network interfaces along with DCF-MAC protocol implementation under different network load by means of OPNET Modeler
\end{abstract}

\section{General Terms}

Node-Mobility Analysis

\section{Keywords}

MANET Network, DSR, Mobility Speed, QoS

\section{INTRODUCTION}

Mobile conferencing, emergency services, disaster recovery and battlefield operations are the few potential applications of MANETs [1-2]. A MANET is a self-conFigd, multi-hop and autonomous group of mobile users that communicate over reasonably slow wireless links and may either operate in a standalone fashion or to be connected to the larger Internet [34]. All network activities such as discovering of network topology and delivering of messages is carried out by the nodes themselves in such networks. Nodes in MANET utilize the same random access wireless channel, cooperating in an intimate manner to engaging themselves in multi-hop forwarding [5]. Due to frequent variations in mobility of nodes in terms of speed, direction and rate, the structure of the network varies dynamically and unpredictably over time and causes route failures. Mobility-induced path failure, which affects packet loss rates, end-to-end delay, throughput and packet delivery fraction/ratio, normalized routing load, is a key obstacle to improving QoS in adhoc networks. Even more critical is the pattern of packet loss. Mobility-induced route failures result in not only random packet losses but instances of bursty packet losses. Hence, it is a challenging task in MANETs to choose effective route to establish the connection between a source and a destination to realize a robust communication even when they are roaming around at different speeds. To analyze the impact of node-mobility over the performance of MANET networks, it is imperative to analyze the movement pattern of mobile nodes. In wireless networks, the widely used mobility model is random waypoint due to its simplicity to implement in the simulation environment for various analyses [6]. The mobility pattern also plays a significant role in determining the routing protocol performance. The routing protocols must be able to respond rapidly to topological changes in the network due to frequent mobility variations. At the same time, due to the limited bandwidth available through mobile radio interfaces, it is essential that the amount of control traffic, generated by the routing protocols is kept at a minimum [7]. Many proactiveand reactive-routing schemes have been reported to provide adequate performance of ad-hoc networks. AODV reactive routing protocol is mostly intended for use by mobile nodes in an ad-hoc network, as it offers quick adaptation to dynamic link conditions, low processing- and memory-overhead, low network utilization and determines unicast routes to destinations within the ad hoc network [8]. The previous research work did not measure the impact of node-mobility speed on performance of DSR route information based MANET at high data rate of $54 \mathrm{Mbps}$ using OFDM radio network interfaces and DCF-MAC protocol implementation in detail. Therefore, it is required to investigate this issue to provide constant internet services to mobile users moving with different speeds in different directions at a different rate with optimum QoS within a MANET network. Our work reported in this paper is focused on the development of economical and accurate AODV route information based IEEE $802.11 \mathrm{~g}$ MANETs at data rate of $54 \mathrm{Mbps}$. The work is carried out by using OFDM radio network interfaces and DCF-MAC protocol implementation under different network load describing the random movement of nodes with varying mobility speed using random mobility model by means of OPNET Modeler 14.5. To analyze the effect of mobility on the QoS performance of this simulative network, both the application oriented metrics (average end-to-end delay, overall network load, throughput, packet delivery ratio) and routing metrics (normalized routing load, number of hops per route) are used.

\section{SIMULATION SETUP}

Using OPNET 14.5 simulator, we have designed and investigated different MANET scenarios with different network sizes of $\left[500 * 500 \mathrm{~m}^{2}, 1000 * 1000 \mathrm{~m}^{2}, 1500 * 1500 \mathrm{~m}^{2}\right]$ with different number of mobile nodes of [20, 40, 60] respectively. The work is demonstrated using voice over IP (VoIP) traffic load applications for simulation interval of 5 minutes as shown in Fig 1 at high data rate of $54 \mathrm{Mbps}$. We take different network size according to the number of nodes as on increasing the number of nodes in a fixed size MANET; there will obvious increase of the congestion problem and the impact of node-speed can not be calculated clearly. Mobility model used is random waypoint model with 
mobility of $500 * 500$ meter [9]. The performance of the MANET network is evaluated by implementing the reactive DSR routing protocol under the impact of different mobility speeds in different scenarios. The WLAN parameters are common to all mobility scenarios as shown in Table 1 [10]. The traffic flows randomly between different workstations placed at different distances in different scenarios as shown in Fig 1. DSR has a unique advantage by virtue of source routing. As the route is part of the packet itself, routing loops, either short-lived or long-lived, cannot be formed as they can be immediately detected and eliminated [11-13]. The simulation parameters of DSR are listed in Table 2 for the proposed setup. The gratuitous reply is enabled and is set to 1 second for reducing the route discovery time. Also, time to handoff packet awaiting route is increased, and DSR Route export is enabled to decrease the congestions in the network. The Random Waypoint Mobility Model [14-15] includes pause times between changes in the direction and/or speed.

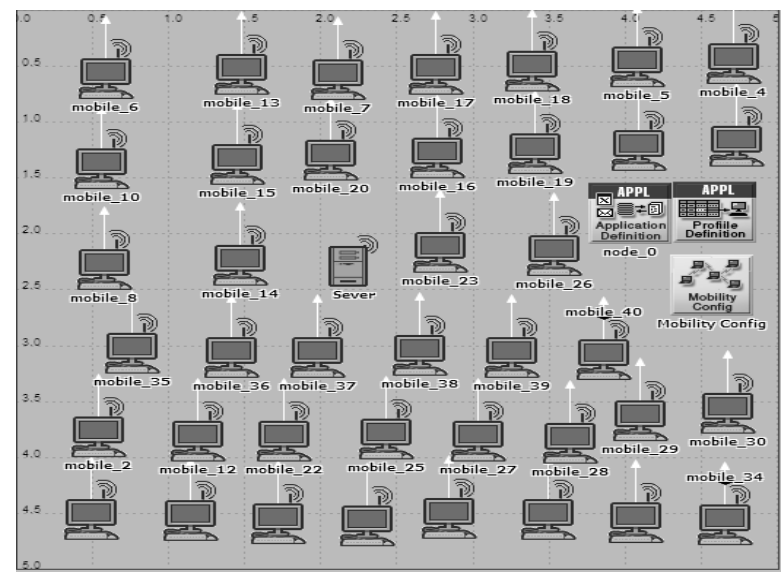

Fig: 1 Model of IEEE 802.11g MANET Network using OPNET 14.5 Simulator

Table 1. Simulation parameters of MANET Network

\begin{tabular}{|c|c|}
\hline Routing Protocol & DSR \\
\hline $\begin{array}{l}\text { Wireless LAN MAC } \\
\text { Address }\end{array}$ & Auto Assigned \\
\hline Physical Characteristics & $\begin{array}{c}\text { IEEE 802.11g } \\
\text { (OFDM) }\end{array}$ \\
\hline Data Rates(bps) & 54 Mbps \\
\hline Transmit Power & 0.005 \\
\hline RTS Threshold & 256 \\
\hline $\begin{array}{c}\text { Packet- Reception } \\
\text { Threshold }\end{array}$ & -95 \\
\hline $\begin{array}{c}\text { Long Retry Limit } \\
\text { Max Receive } \\
\text { Lifetime(seconds) }\end{array}$ & 4 \\
\hline Buffer Size(bits) & 102400000 \\
\hline
\end{tabular}

A mobile node begins by staying in one location for a pause time. Once this time expires, the mobile node chooses a random destination as well as a speed that is uniformly distributed between [0, Max_speed]. It then travels towards the newly chosen destination at the selected speed. Upon arrival, the mobile node takes another break before starting the process again. To have maximum mobility in over simulation environment, we have taken pause time to 0 seconds.

Table 2. Simulation parameters- DSR

\begin{tabular}{|c|c|}
\hline $\begin{array}{c}\text { Gratuitous Route } \\
\text { Reply }\end{array}$ & $1 / \mathrm{sec}$. \\
\hline $\begin{array}{c}\text { Time to Handoff } \\
\text { Packet Awaiting } \\
\text { Route }\end{array}$ & $30 \mathrm{sec}$. \\
\hline DSR Route Export & Enabled \\
\hline $\begin{array}{c}\text { Time b/w } \\
\text { Retransmission } \\
\text { Request }\end{array}$ & $0.05 \mathrm{sec}$. \\
\hline $\begin{array}{c}\text { Non-propagation } \\
\text { Request Timer }\end{array}$ & $0.03 \mathrm{sec}$ \\
\hline Route Expiry Time & 500 \\
\hline
\end{tabular}

\section{RESULT \& DISCUSSION}

To evaluate the performance of DSR route information based IEEE $802.11 \mathrm{~g}$ MANET under the impact of mobility speed of nodes at high data rate of $54 \mathrm{Mbps}$, we have determined the various QoS parameters such as throughput, end-to-end delay, packet delivery ratio and network load. The Fig 2 shows a comparison for throughput, the loss rate as seen by the transport layer and reflects the completeness and accuracy of the routing protocol, as a function of mobility speed at different network sizes and number of traffic sources. From 2(a) graph, it is clear that DSR enabled network of 20 nodes with mobility speed of uniform [1.4-1.6] has the highest throughput virtually $313.423 \mathrm{kbps}$ on average. The throughput drops to $310.101 \mathrm{kbps}$ at uniform [0.8-1.0] speed, to 312.063 kbps at uniform [0.4-0.6] speed, and to $303.808 \mathrm{kbps}$ for stable nodes. This implies that the small sized DSR enabled MANETs perform poor in case of stationary nodes. The throughput improves at low speeds, decreases at moderate speed and improves again at mobility speed of uniform [1.41.6].

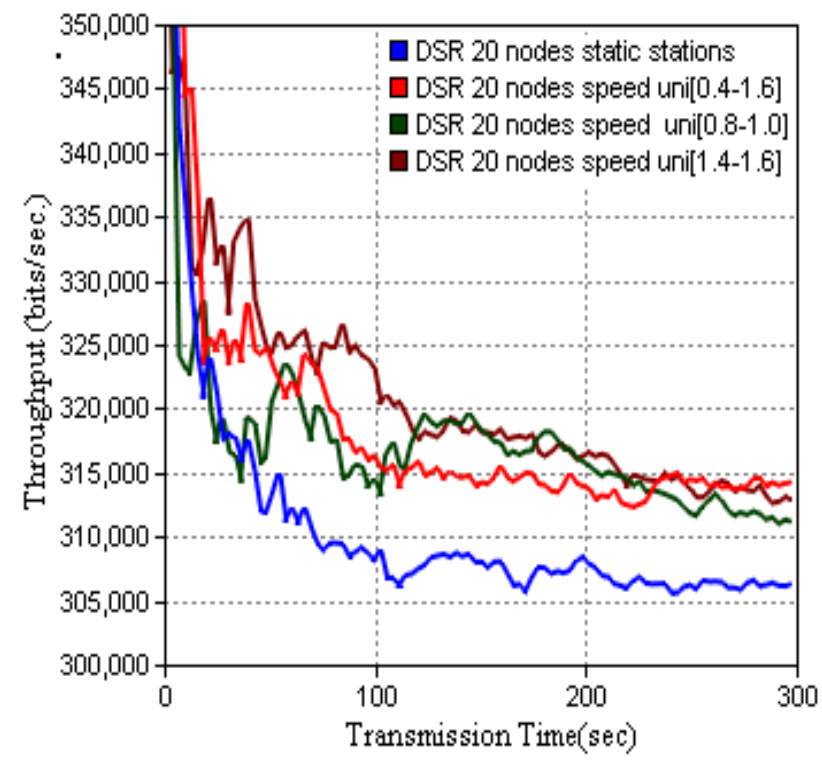

Fig: 2(a) Throughput Comparison of 20 Nodes MANET Network of $500 * 500 \mathrm{~m}^{2}$ at different mobility speeds 


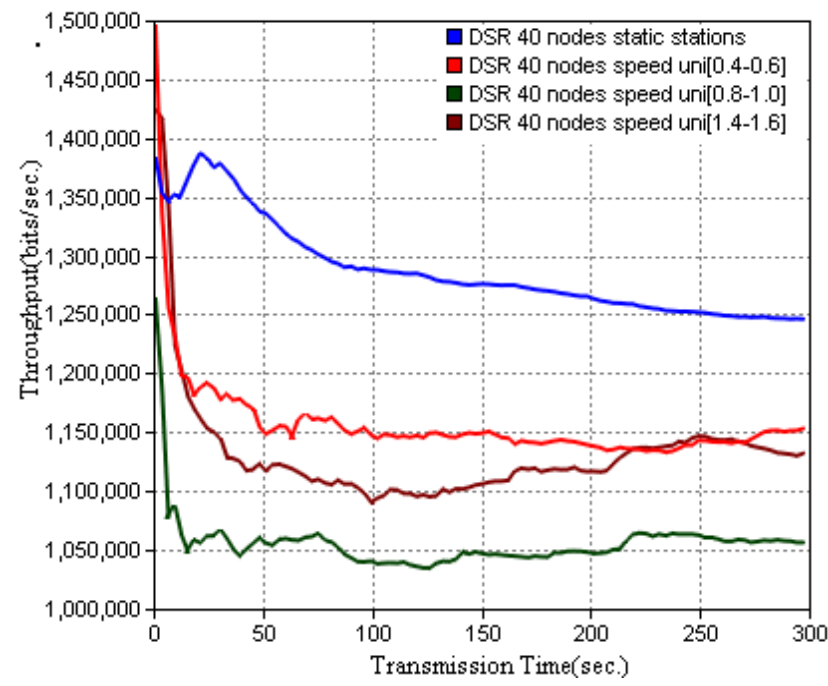

Fig: 2(b) Throughput Comparison of 40 Nodes MANET Network of $1000 * 1000 \mathrm{~m}^{2}$ at different mobility speeds

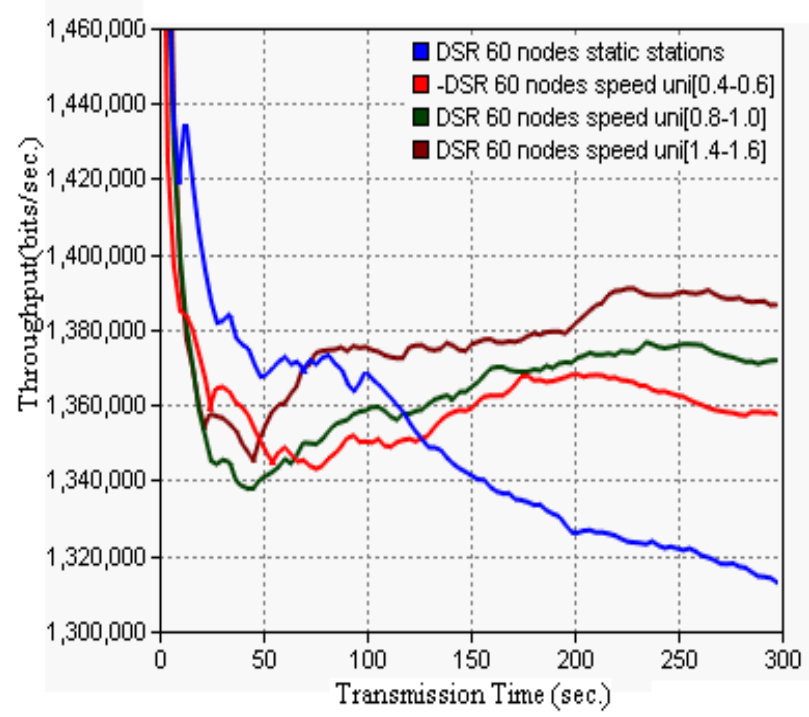

Fig: 2(c) Throughput Comparison of 60 Nodes MANET Network of $1500 * 1500 \mathrm{~m}^{2}$ at different mobility speeds

From graph 2(b), as the number of nodes increase to 40, throughput of stationary node network become best (i.e. $1257.896 \mathrm{kbps}$ ), and starts decreasing with an increase in speed, but as speed of mobile nodes are further increased to 1 $\mathrm{m} / \mathrm{s}$, network throughput again starts improving. This is due to the reason that for moderate DSR networks, nodes usually get clustered with low mobility, which leads to network congestion in certain regions in the presence of high traffic. This causes link layer feedback to report link failures even when the nodes are relatively stable and the physical link exists between nodes. Such spurious link failures lead to the new route discoveries and thus, decrease in throughput at low mobility speed occurs. In case of large sized DSR enabled MANETs, consist of 60 nodes, there is a large drop in throughput for static stations. This is due to denser environment which causes wastage of bandwidth. The throughput performance starts improving with the increase in mobility speed, and the network has highest throughput at [1.4-1.6]m/s as shown in Fig 2(c).

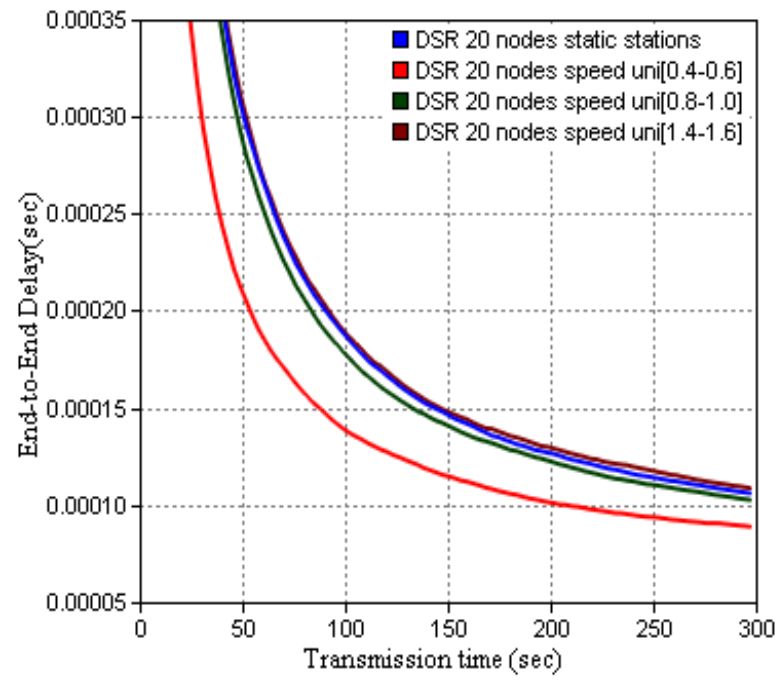

Fig: 3(a) End-to-End Delay Comparison of 20 Nodes MANET Network of $500 * 500 \mathrm{~m}^{2}$ at different mobility speeds

Thus, our simulation results imply that better throughput is reported with an increase in mobility speed for small- (20 nodes) and large- networks (60 nodes), but in case of moderate networks (40 nodes); a poor throughput performance is achieved. Fig 3 calculates the average packet end-to-end delay of each transmitted packet during the simulation period as a function of mobility speed. It includes all possible delays caused by buffering during route discovery latency, queuing at the interface queue, retransmission delays at MAC, propagation- and transfer-time. From the graph 3(a), it is observed that the average end-to-end delay for 20 node is best i.e. $0.019 \mathrm{~ms}$ at speed of $[0.4-0.6] \mathrm{m} / \mathrm{s}$, and is worst i.e. $0.028 \mathrm{~ms}$ at high mobility speed of [1.4-1.6]m/s. This implies that for small sized DSR based MANETs, there is increase end-to-end delay with an increase in mobility speed. This is due to the fact that, the chance of caches being stale is quite high at high node-mobility.

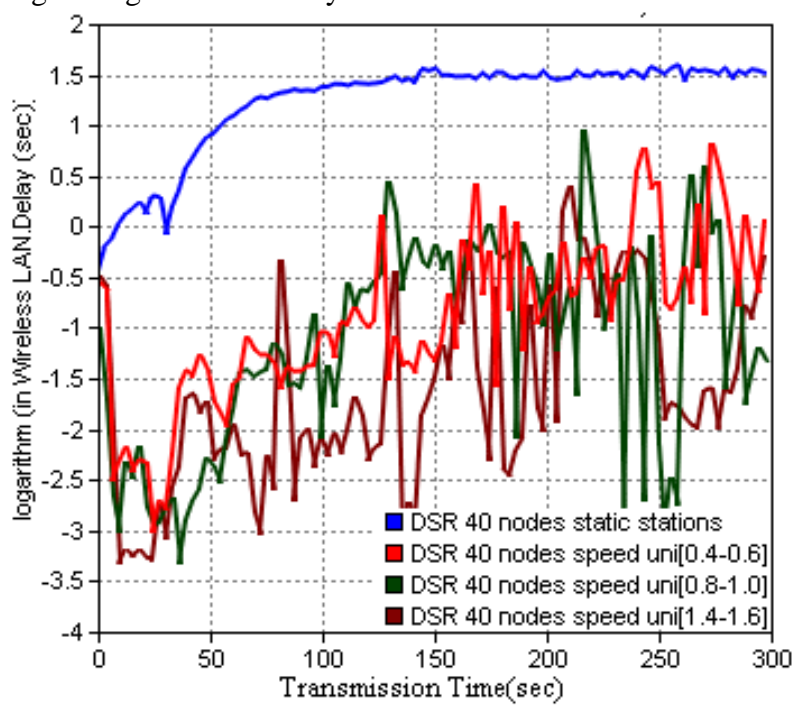

Fig: 3(b) End-to-End Delay Comparison of 40 Nodes MANET Network of $1000 * 1000 \mathrm{~m}^{2}$ at different mobility speeds 


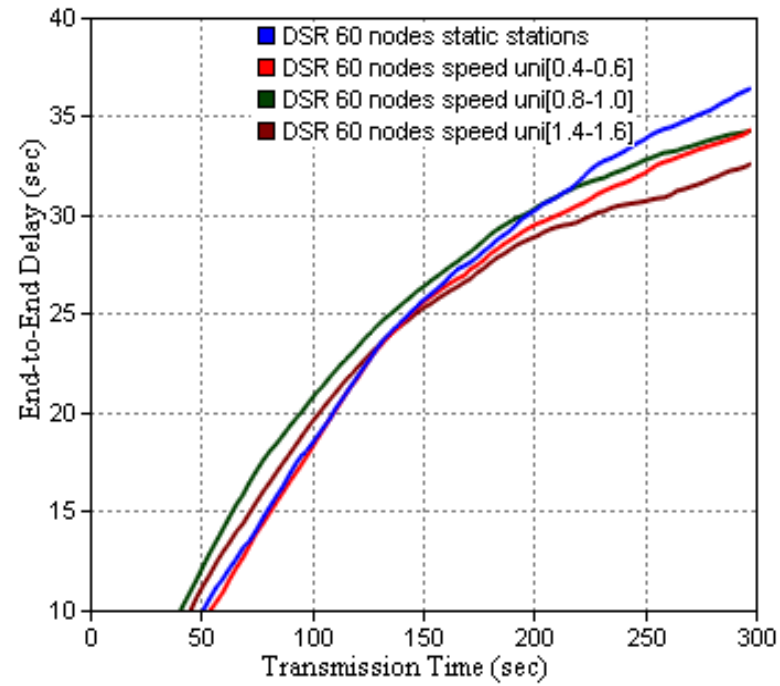

Fig: 3(c) End-to-End Delay Comparison of 60 Nodes MANET Network of $1500 * 1500 \mathrm{~m}^{2}$ at different mobility speeds

With the increase in the number of source nodes, these delays increase sharply throughout the simulation period for all mobility speeds, shown in Fig 3(b, c) and Table 3. This is due to a high level of network congestion and multiple access interferences at certain regions of the ad hoc network DSR has no mechanism for load balancing, that is, choosing routes in such a way that the data traffic can be more evenly distributed in the network. Also, it is observed that, for moderate- and large- sized MANETs, the end-to end delay decreases with the increase in mobility speed as depicted in Figs 3(b, c).

Fig 4 calculates the overall network load as a function of mobility speed. For DSR enabled MANETs consisting of 20 mobile nodes, the initial load is very high for all mobility speeds and decreases sharply with simulation period as shown in Fig 4(a). The network load is maximum i.e. $311.809 \mathrm{kbps}$ at node-speed of [1.4-1.6] m/s, which decreases sharply to $307.615 \mathrm{kbps}$ at the end of simulation time. As the mobility speed reduced to $[0.8-1.0] \mathrm{m} / \mathrm{s}$ and to $[0.4-0.6] \mathrm{m} / \mathrm{s}$, the network load decreases to $308.548 \mathrm{kbps}$ and $310.564 \mathrm{kbps}$ respectively. Accordingly, the network load is computed as $302.289 \mathrm{kbps}$ for stable nodes. Though at a lower speed i.e. [0.4-0.6] $\mathrm{m} / \mathrm{s}$, the initial network load is very high, but with an increase in simulation time, it decreases sharply as shown in Fig 4(a). Network load increases with mobility speed is due to reason that when a route discovery is initiated, the large number of replies received in response is associated with high MAC overhead [16]. This causes an increase in interference to data traffic. Hence, the cache staleness and high MAC overhead together result in significant degradation in the performance of DSR enabled MANETs at high node-mobility. Thus, even when a spurious link failure is reported, DSR benefits from caching considerably by salvaging at intermediate nodes and using alternate routes at the sources [8]. Overall network load is increased sharply further as source nodes increases for all mobility speeds as shown in Fig $4(b, c)$ respectively. Increase in overall network load with increasing in number of nodes and mobility speed is due to increase in additional bandwidth consumed by the data packets that are dropped, depending on the number of hops as they travel before being dropped.

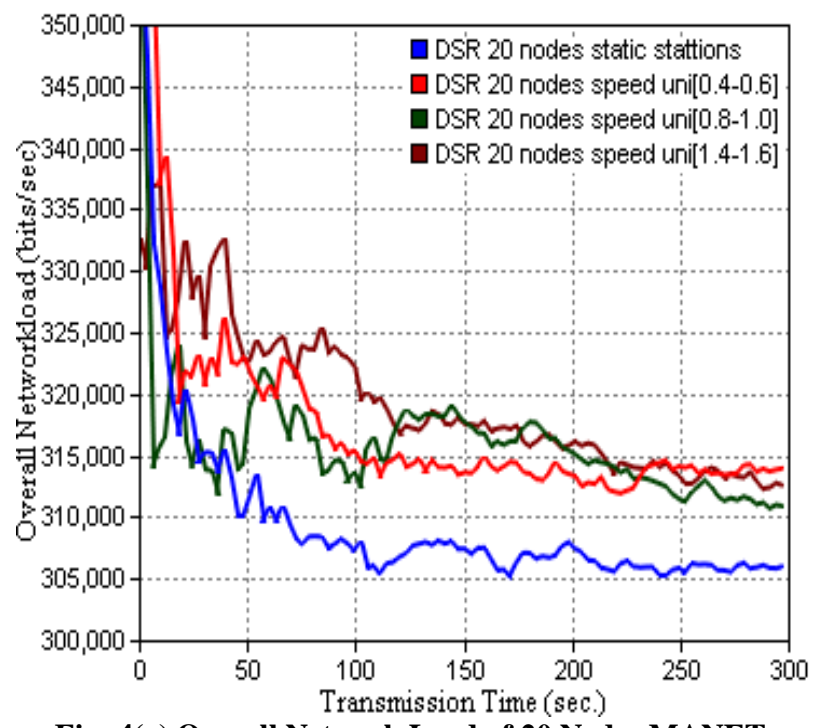

Fig: 4(a) Overall Network Load of 20 Nodes MANET Network of $500 * 500 \mathrm{~m}^{2}$ at different mobility speeds

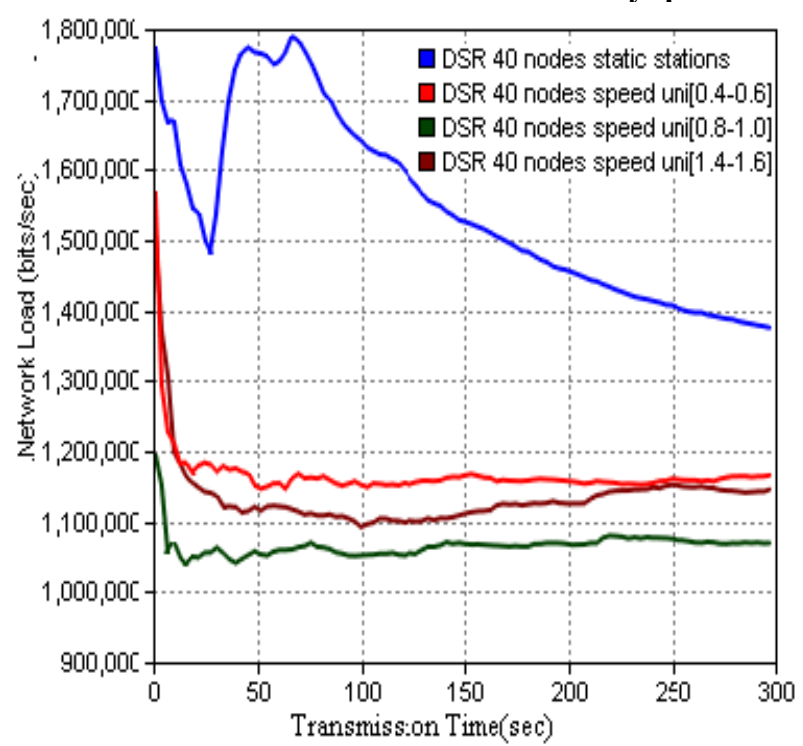

Fig: 4(b) Overall Network Load of 40 Nodes MANET Network of $1000 * 1000 \mathrm{~m}^{2}$ at different mobility speeds

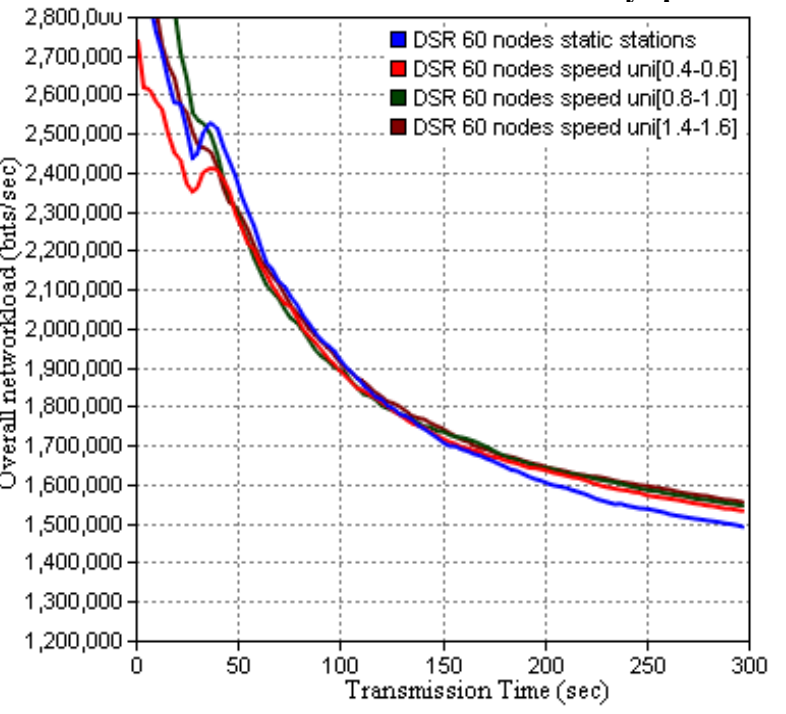

Fig: 4(c) Overall Network Load of 60 Nodes MANET 


\section{Network of $1500 * 1500 \mathrm{~m}^{2}$ at different mobility speeds}

Fig 5 shows the calculation of the number of hops per routs of DSR route information based IEEE 802.11g MANET at different speeds using different source nodes. It is observed that, for 20 nodes, a reduced amount of the impact of nodemobility is measured over the number of hopes per routs at all the speed levels. For higher number of nodes i.e. for 40 nodes, the computed number of hops per route is high, in case of stable nodes, and then starts decreasing at low speeds. At node-speed above $1 \mathrm{~m} / \mathrm{s}$, number of hops per route starts increasing again and becomes maximum. In case of 60 nodes, the computed number of hopes per routs is unusually high and increases with an increase in node speed. The computed number of hops per route increases with an increase in mobility speed and number of nodes and causes addition bandwidth consumption, which further increases the overall network load.

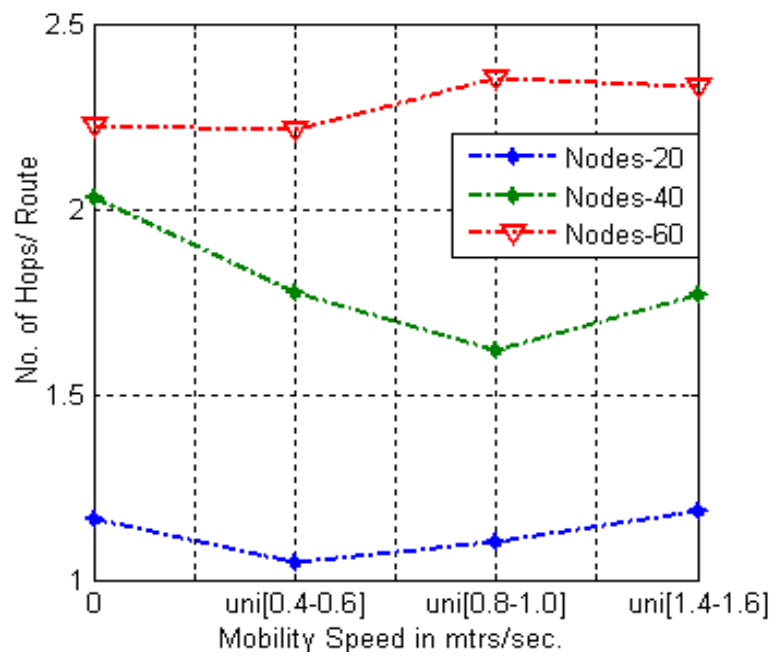

Fig: 5 Number of Hopes per Routs of different MANET traffic nodes Network at different mobility speeds

Fig 6 shows the calculation of packet delivery ratio/fraction (PDR) at different speeds at different source nodes. The graph shows that in DSR enabled MANETs, PDR decreases as the number of mobile nodes increases from 20 to 60 nodes. This is due to reason that an increase in number of nodes causes the collision during packet transmission in packet delivery. In small DSR enabled networks (20 mobile-nodes), effect of increase in mobility speed is least, and PDR remains almost 1 at all mobility speeds, but as mobile nodes are increased to 40 (moderate network) PDR drops to 0.716348 for stable nodes. Then, it starts improving with an increase in mobility speed and becomes almost 1.001969 at [1.4-1.6] m/s. When mobile nodes are further increased to 60 i.e. for large networks, there is a large PDR drop at all mobility speeds. This drop increased further with an increase in mobility speed as shown in Fig 6. Our results imply that DSR enabled MANETs network perform inadequately in term of PDR in more "stressful" situations (i.e., larger numbers of nodes and/or higher mobility). However, it performs better in less stressful situations. The reason is the aggressive use of route caching in DSR enabled MANETs as such caching provides a significant benefit up to a certain extent. With higher loads, the extent of caching is deemed too large to benefit performance [17-18]. The measured values of QoS matrices, used in our work, as a function of nodes and node-mobility is given in tabular form in Table 3 and 4.

Fig 7 shows logarithmic normalized routing load (NRL), defined as the fraction of all routing control packets sent by all nodes over the number of received data packets at the destination nodes to compute the additional bandwidth consumed by overhead to deliver the data packets. From Fig 7 , it is observed that DSR's normalized routing load is fairly stable with an increasing number of source nodes from 20 to 40 , even though its delivery and delay performance get increasingly worse. A relatively stable normalized routing load is a desirable property for scalability of the protocols, since further increasing nodes to 60 , routing load increases linearly with the number of mobile nodes. Also, it is observed DSR NRL performance starts degrading with an increase in mobility speed for all three simulation networks.

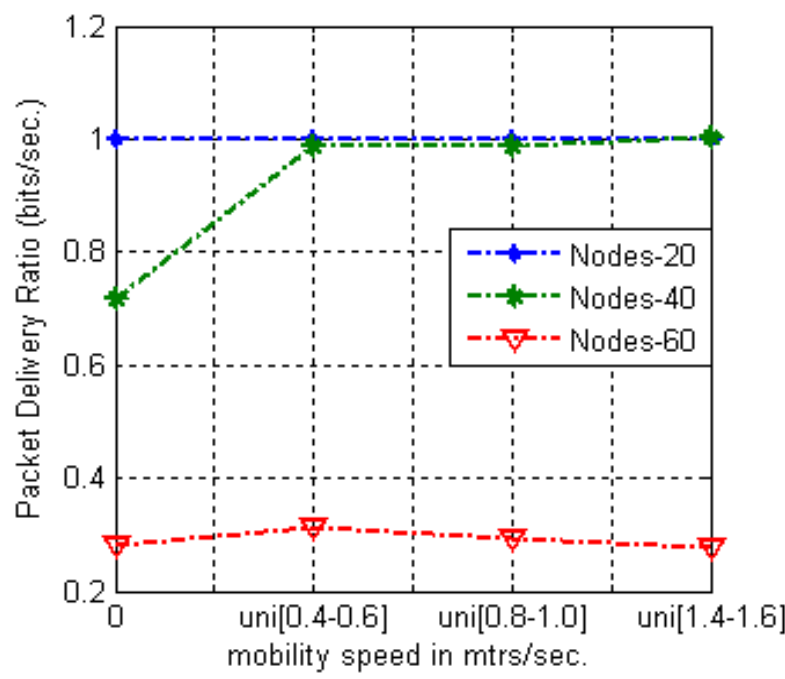

Fig: 6 Packet Delivery Ratio of different MANET traffic nodes Network at different mobility speeds

This is due to reason that, with high mobility, the number of RTSs sent is often twice the number of CTSs received. This is due to frequent RTS retransmissions for errors due to collisions or link loss due to which routing load consumed a significant amount of bandwidth [8]. The measured values of QoS matrices, used in our work, as a function of nodes and node-mobility is given in tabular form in Table 5.

Table 3. PDR and Average Throughput Comparison using various mobility speed

\begin{tabular}{|c|c|c|c|c|c|c|}
\hline \multirow{2}{*}{$\begin{array}{c}\text { Mobilit } \\
\text { y Speed } \\
\text { vs. } \\
\text { Nodes } \\
\end{array}$} & \multicolumn{3}{|c|}{$\begin{array}{c}\text { Packet Delivery } \\
\text { Ratio }\end{array}$} & \multicolumn{3}{|c|}{$\begin{array}{c}\text { Average Throughput } \\
\text { (kbps) }\end{array}$} \\
\hline & 20 & 40 & 60 & 20 & 40 & 60 \\
\hline $\begin{array}{c}\text { Static } \\
\text { Stations } \\
\end{array}$ & 1 & $\begin{array}{l}0.71 \\
634 \\
\end{array}$ & $\begin{array}{l}0.28 \\
288 \\
\end{array}$ & $\begin{array}{l}303 . \\
808\end{array}$ & $\begin{array}{c}1257 . \\
896\end{array}$ & $\begin{array}{c}1320 . \\
431\end{array}$ \\
\hline $\begin{array}{c}{[0.4-} \\
0.6] \mathrm{m} / \mathrm{s} \\
\end{array}$ & $\begin{array}{l}0.99 \\
999 \\
\end{array}$ & $\begin{array}{l}0.98 \\
893\end{array}$ & $\begin{array}{l}0.31 \\
127\end{array}$ & $\begin{array}{l}312 . \\
063\end{array}$ & $\begin{array}{c}1130 . \\
588\end{array}$ & $\begin{array}{c}1329 . \\
979\end{array}$ \\
\hline $\begin{array}{c}{[0.8-} \\
1.0] \mathrm{m} / \mathrm{s}\end{array}$ & $\begin{array}{l}0.99 \\
997\end{array}$ & $\begin{array}{l}0.98 \\
656\end{array}$ & $\begin{array}{l}0.29 \\
270\end{array}$ & $\begin{array}{l}310 . \\
101\end{array}$ & $\begin{array}{c}1031 . \\
426\end{array}$ & $\begin{array}{c}1336 . \\
229\end{array}$ \\
\hline $\begin{array}{c}{[1.4-} \\
1.6] \mathrm{m} / \mathrm{s}\end{array}$ & $\begin{array}{l}0.99 \\
999\end{array}$ & $\begin{array}{l}1.00 \\
196\end{array}$ & $\begin{array}{c}0.27 \\
83\end{array}$ & $\begin{array}{l}313 . \\
423\end{array}$ & $\begin{array}{c}1105 . \\
568\end{array}$ & $\begin{array}{c}1349 . \\
312\end{array}$ \\
\hline
\end{tabular}




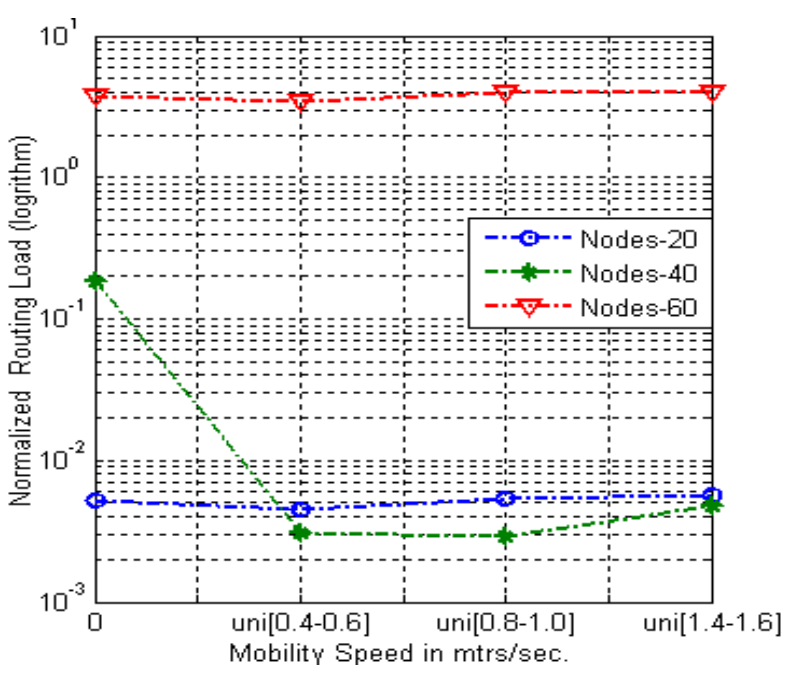

Fig: 7 Normalized Routing Load of different MANET traffic nodes Network at different mobility speeds

Table 4. End-to-End Delay and Network Load Comparison using various mobility speeds

\begin{tabular}{|c|c|c|c|c|c|c|}
\hline \multirow{2}{*}{$\begin{array}{c}\text { Mobili } \\
\text { ty } \\
\text { Speed } \\
\text { vs. } \\
\text { Nodes }\end{array}$} & \multicolumn{3}{|c|}{$\begin{array}{c}\text { Normalized Routing } \\
\text { Load (Seconds) }\end{array}$} & \multicolumn{3}{|c|}{ No. of Hops/Route } \\
\hline & 20 & 40 & 60 & 20 & 40 & 60 \\
\hline $\begin{array}{c}\text { Static } \\
\text { Station } \\
\text { s }\end{array}$ & $\begin{array}{c}0.005 \\
177\end{array}$ & $\begin{array}{c}0.184 \\
462\end{array}$ & $\begin{array}{c}3.702 \\
914\end{array}$ & $\begin{array}{c}1.16 \\
40\end{array}$ & $\begin{array}{c}2.029 \\
80\end{array}$ & $\begin{array}{c}2.222 \\
907\end{array}$ \\
\hline $\begin{array}{c}0.4- \\
0.6] \mathrm{m} / \\
\mathrm{s}\end{array}$ & $\begin{array}{c}0.004 \\
553\end{array}$ & $\begin{array}{c}0.003 \\
105\end{array}$ & $\begin{array}{c}3.460 \\
784\end{array}$ & $\begin{array}{c}1.04 \\
61\end{array}$ & $\begin{array}{c}1.776 \\
54\end{array}$ & $\begin{array}{c}2.214 \\
783\end{array}$ \\
\hline $\begin{array}{c}0.8- \\
1.0] \mathrm{m} / \\
\mathrm{s}\end{array}$ & $\begin{array}{c}0.005 \\
445\end{array}$ & $\begin{array}{c}0.002 \\
880\end{array}$ & $\begin{array}{c}3.977 \\
432\end{array}$ & $\begin{array}{l}1.10 \\
24\end{array}$ & $\begin{array}{c}1.619 \\
56\end{array}$ & $\begin{array}{c}2.351 \\
57\end{array}$ \\
\hline $\begin{array}{c}{[1.4-} \\
1.6] \mathrm{m} / \\
\mathrm{s}\end{array}$ & $\begin{array}{c}0.005 \\
697\end{array}$ & $\begin{array}{c}0.004 \\
847\end{array}$ & $\begin{array}{c}3.996 \\
293\end{array}$ & $\begin{array}{c}1.18 \\
42\end{array}$ & $\begin{array}{c}1.768 \\
98\end{array}$ & $\begin{array}{c}2.331 \\
615\end{array}$ \\
\hline
\end{tabular}

\section{CONCLUSION}

This work emphasized on a simulation model of DCF route information based IEEE 802.11g MANET at high data rate of 54 Mbps using OFDM radio network interfaces and DCFMAC protocol implementation to demonstrate the impact of different mobility speed of nodes and number of nodes. The general observation from our simulation is that for application-oriented metrics such as delay, network load, throughput, PDR, number of hopes per route, normalized routing load, a random behavior is observed. The general observation from the simulation is that for applicationoriented metrics such as delay, network load and throughput, DSR enabled MANETs outperforms in less "stressful" situations i.e. smaller number of nodes, with low nodemobility. The poor delay and throughput performances of DSR enabled MANETs are mainly attributed to aggressive use of caching, and lack of any mechanism to expire stale routes or determine the freshness of routes. Aggressive caching, however, seems to help DSR at less stressful situations (low mobility speeds and small node density) and also keeps its routing load down. It is observed that mechanisms to expire routes and/or determine freshness of routes in the route cache will benefit DSR's performance significantly.

Table 5. Normalized Routing Load and No. of Hops/Route Measurements using various mobility speeds

\begin{tabular}{|c|c|c|c|c|c|c|}
\hline & \multicolumn{3}{|c|}{$\begin{array}{c}\text { End-to-End Delay } \\
\text { (seconds) }\end{array}$} & \multicolumn{3}{c|}{$\begin{array}{c}\text { Average Network } \\
\text { Load } \\
\text { (kbps) }\end{array}$} \\
\cline { 2 - 7 } $\begin{array}{c}\text { Mobility } \\
\text { Speed } \\
\text { vs. } \\
\text { Nodes }\end{array}$ & $\mathbf{2 0}$ & $\mathbf{4 0}$ & $\mathbf{6 0}$ & $\mathbf{2 0}$ & $\mathbf{4 0}$ & $\mathbf{6 0}$ \\
\hline $\begin{array}{c}\text { Static } \\
\text { Stations }\end{array}$ & 0.000 & 13.7 & 22.6 & 302.2 & 1544 & 18791 \\
\hline$[0.4-$ & 0.000 & 0.17 & 21.9 & 310.5 & 1166 & 18606 \\
$0.6] \mathrm{m} / \mathrm{s}$ & 20 & 180 & 312 & 64 & 727 & 23 \\
\hline$[0.8-$ & 0.000 & 0.18 & 23.2 & 308.5 & 1066 & 19106 \\
$1.0] \mathrm{m} / \mathrm{s}$ & 27 & 946 & 815 & 48 & 023 & 27 \\
\hline$[1.4-$ & 0.000 & 0.08 & 21.9 & 311.8 & 1135 & 19007 \\
$1.6] \mathrm{m} / \mathrm{s}$ & 28 & 377 & 386 & 09 & 017 & 78 \\
\hline
\end{tabular}

\section{REFERENCES}

[1] Perkin C., Bhagwat P., 1994 "Highly Dynamic Destination Sequenced Distance Vector Routing for mobile computers", ACM SIGCOMM, computer communication review, vol. 24, issue 4, 1994, 234-244.

[2] Hushaidan W., Qatawneh A., Sliet A., Qatawneh M., 2011 " A cluster-Based Approach for supporting QoS in Mobile Ad Hoc Networks", International Journal of Digital Content Technology and its Applications(JDCTA), vol. 5, 2011,no. 1.

[3] Mobile Ad-hoc Networks (MANET), URL:http://ietf.org/html.charters/manet-charter .html, 1998.

[4] Toh K., 2002, "Ad Hoc mobile wireless networks: protocols and systems", 1st edition. New Jersey (USA): Prentice Hall.

[5] Feeney L.M., "A Taxonomy for Routing Protocols in Mobile Ad-hoc Networks", Technical Report, Swedish Institute of Computer Science, Sweden, 1999.

[6] Camp T., Boleng J., Davies V. 2002 "A Survey of Mobility Models for Ad Hoc Network Research", Wireless Communication \& Mobile Computing (WCMC): vol. 2, no. 5, 2002, 483-502.

[7] Elizabeth M., Toh C., 2004 "A Review of Current Routing Protocols for Ad Hoc Mobile Wireless Networks", pp. 1-22, Ad Hoc Networks 2, 2004.

[8] Perkins C., Royer E. B. and Das S., 2003 “Ad hoc On-Demand Distance Vector (AODV) Routing - Internet Draft", IETF Network Working Group, RFC 3561, 2003, 1-38.

[9] P. Johansson et al., 1999 "Routing Protocols for Mobile Ad-hoc Networks- A Comparative Performance Analysis," In Proceeding of IEEE/ACM MOBICOM '99, 195-206.

[10] MANET, Operation Manual for OPNET, 2007.

[11] Abolhasan M., Wysocki T., Dutkiewic E., 2004 "A Review of Routing Protocols for Mobile Ad hoc Networks", Elsevier, Ad-hoc Networks 2, 2004, 1-22.

[12] Johnson B., Maltz A., Hu C., 2004 "The Dynamic Source Routing Protocol for Mobile Ad Hoc Networks (DSR)", draft-ietf-manet-dsr-10.txt, Internet-draft, 2004.

[13] Johnson B., Maltz A., 1996 "Dynamic Source Routing in Ad Hoc Networks", Mobile Computing, T. 
Imielinski and H. Korth, Eds. Kulwer Publ., 1996, 15281.

[14] Larsson T., Hedman N., 1998 "Routing Protocols in Wireless Ad-hoc Networks - A Simulation Study", Lulea University of Technology, Stockholm, 1998.

[15] Suresh A., 2005 "Performance Analysis of Ad Hoc On-demand Distance Vector Routing(AODV) Using OPTNET Simulator", University of Bremen- 11, 2005.

[16] Perkins C., Royer E., Das R. , 2001 "Performance Comparison of Two On-Demand Routing Protocols for
Ad Hoc Networks", IEEE Personal Communications, 2001, 16-28.

[17] K. Fall and K. Varadhan, Eds., ns notes and documentation, 1999; mash.cs.berkeley.edu/ns/.

http://www-

[18] G. Holland and N. H. Vaidya, 1999 "Analysis of TCP Performance Over Mobile Ad Hoc Networks", In the Proceeding of IEEE/ACM MOBICOM '99, Seattle, 219-30. 